\title{
ESTUDO, ESTUDAR, SER ESTUDANTE NO ENSINO SUPERIOR - CONDIÇÕES GERAIS IMANENTES E CONTEXTO SOCIOECONÔMICO CULTURAL DAS CLASSES POPULARES
}

\section{STUDY, STUDYING, BEING A STUDENT IN COLLEGE - IMMANENT GENERAL CONDITIONS AND CULTURAL SOCIOECONOMIC CONTEXT OF THE LOWER CLASS}

\author{
Iael de Souza ${ }^{1}$ \\ Ryan Ribeiro de Azevedo ${ }^{2}$
}

\section{RESUMO}

Este artigo é resultado de um estudo com alunos das classes populares egressos ao ensino público superior, do campus de Picos, da Universidade Federal do Piauí, dos cursos de licenciatura em História, Pedagogia e Matemática, criados através do REUNE, que comprova que esses estudantes não sabem o significado do que é o estudo, o estudar e o ser estudante. Uma reflexão (re)contextualizada e (re)significativa é realizada de uma perspectiva ontológica/teleológica - contribuição teórica desse trabalho - a fim de potencializar a criação subjetiva para uma mudança atitudinal objetiva, apontando e sugerindo uma reestruturação curricular e a diretriz de um método de estudo reapropriado e recontextualizado mediante as condições e circunstâncias da classe social a que os estudantes pertencem e segundo as necessidades imanentes as atividades do estudo, estudar e ser estudante.

PALAVRAS-CHAVE: Estudo - Ser estudante - Trabalhador estudante.

\begin{abstract}
This paper is the result of a study consisting of lower-class undergraduates enrolled in college, on a Picos campus, from an Piauí's Federal University, in the Bachelor's programs of History, Pedagogy and Mathematics, established by REUNE, confirming such students don't know the meaning of what the study, studying and being a student is. A (re)contextualized and (re)significative reflection is performed on a(n) ontological/teleological perspective - theoretical contribution of this paper - in order to


enhance subjective creation toward an objective attitudinal modification, by pointing out and suggesting a curricular restructure and the guideline of a reappropriate and recontextualized method of study on account of the conditions and circumstances regarding the social class that these undergraduates belong to and according to the immanent needs of the activities related to study, studying and being a student.

KEYWORDS: Study - Being a student - Working undergraduates.

\section{INTRODUÇÃO}

Partimos do entendimento de que o ato de estudar, o estudo é uma atividade produtiva, um trabalho, que exige e impõe, como condição sine qua non para sua realização, determinados procedimentos, atitudes, comportamentos inexoráveis e pressupostos a seu próprio propósito, qual seja, a captação do movimento do real, a necessidade de construção das mediações não aparentes da realidade que só são possíveis através da atividade do pensamento, do concreto pensado, a fim de que o ser social possa dar respostas mais adequadas e eficientes as suas necessidades, sistematizando o conhecimento sociocultural acumulado pela humanidade e garantindo sua reprodução e a do gênero humano.

Trata-se de uma compreensão embasada numa perspectiva ontológica e teleológica, ou seja, que todas as atividades humanas são respostas dadas e criadas às necessidades e reprodução do ser social pela complexificação da vida em sociedade, sendo as ações humanas finalísticas e históricas, equacionamento de situações concretas. Mas não é essa a concepção hegemônica para os estudantes do ensino superior, nem na academia, de forma geral. Através de um estudo empreendido pelos autores entre o segundo semestre do período letivo de 2010 ao primeiro semestre do período letivo de 2012, com discentes egressos dos cursos de licenciatura em História, Pedagogia e Matemática do campus de Picos, da Universidade Federal do Piauí, criados através do REUNE (Reestruturação e Expansão do Ensino Superior), na cidade de Picos, verificou-se que não há clareza, nem segurança, em definir o que seja estudo, estudar e ser estudante, muito menos as condições essenciais inerentes a essas ações. 
O presente artigo é uma análise reflexiva dos dados levantados através do presente estudo, realizado durante as primeiras semanas de aula que ministramos nos referidos cursos e suas respectivas turmas, que variam de 40 a 57 alunos. Na abordagem, foram formuladas, oralmente, duas questões: a) o que vocês entendem por estudo, estudar, ser estudante; b) quais seriam as características e propriedades imanentes específicas a cada uma dessas ações. As falas foram posteriormente registradas para comparação, análise e reflexão.

Também efetuamos uma revisão de algumas das principais pesquisas, estudos e análises teóricas que tratam da questão do ensino superior para as classes populares. Embora tenham um outro foco, utilizamos os dados e análises realizadas para demonstrar que independente da classe social que pertençam os discentes, é necessário que se apropriem, e estejam cônscios, do significado ontológico e teleológico do estudo, do estudar e do ser estudante, a fim de que possam fazer as reconstruções necessárias a sua condição e contexto socioeconômico cultural de classe, impedindo o rebaixamento de sua formação intelectual e humana pelas limitações e delimitações impostas por sua condição de classe.

Outro ponto a salientar é a contribuição para a reflexão teórica da redimensionalização conceitual do estudo, do estudar e do ser estudante, potencializando a criação das condições subjetivas para a concretização objetiva de uma mudança atitudinal por parte dos discentes, pressuposto incondicional para o trabalho de enfrentamento e superação das debilidades, deficiências e lacunas de sua formação escolar pregressa, dado que a mudança começa pela mudança daquele que vê, do modo como vê, reiterando a máxima socrática de que uma vida irrefletida não vale a pena ser vivida.

Por fim, no intuito de auxiliar os discentes no enfrentamento das especificidades adversas de seu contexto e condição socioeconômico cultural de classe, propomos: a) a reflexão coletiva de uma reestruturação curricular em resposta as deficiências e defasagens do processo de escolarização nos níveis fundamental e médio e b) uma metodologia de estudo, conforme sugerida por Ruiz (1980), reapropriada e recontextualizada pelos estudantes, que a planejarão mediante a reconstrução da apropriação do significado ontológico e teleológico do que é o estudo, o estudar e ser estudante, refletindo sobre os condicionamentos e determinações impostos por sua condição de classe. 


\section{ENTREPOSTO}

As novas políticas de acesso - oficialmente propagadas como democratização do ensino superior - e expansão ao e do ensino superior ${ }^{3}$, bem como suas complexas implicações no caráter, produção e significado das Universidades Públicas, como discutidos por Lucas e Leher (2001); Barreto e Leher (2008); Gentili e Silva (2010); Sguissard (2005); Jimenez (2004); Lombardi, Saviani e Sanfelice (2005), promoveram mudanças substantivas e acentuadas no perfil do corpo discente, uma vez que o acesso dos segmentos das classes populares às instituições de ensino superior tiveram um aumento significativo, como ilustram, por exemplo, Pavão (2007) e Britto (et. al. 2008).

Porém, esse acesso não significa democratização, já que esta pressupõe a garantia de condições isonômicas em termos de sistematização do processo de formação escolar anterior - além de outras condições, como expostas por Lucas e Leher (2001) e Zago (2006) -, o que efetivamente inexiste, dificultando o processo de adaptação e continuidade da escolarização, dado que os ingressantes não aprenderam, não desenvolveram e não incorporaram os hábitos e atitudes inerentes e pressupostos a atividade produtiva de estudar, o que comprovam os estudos realizados por Costa e Cunha (2007), Piotto (2008) e Zago (2006) e dos quais falaremos no presente artigo.

O processo de escolarização e formação científico-cultural das camadas populares é marcado pela falta de sistematização significativa do conhecimento sociocultural, técnicocientífico acumulado pelos homens; pela inexistência de vivências e experiências de pesquisa científica que contribuam para a maturação e elevação físico-intelectual (físico porque relativo a construção, aprendizagem e desenvolvimento dos hábitos de estudo necessários à produção do conhecimento científico) desses estudantes.

A consequência imediata da precariedade das condições da formação dos segmentos das classes populares manifesta-se logo no ingresso ao ensino público superior, nas dificuldades em compreender e acompanhar as discussões e reflexões, em desenvolver e produzir o pensamento cientificamente, além de outras deficiências e defasagens que acabam contribuindo para diminuir a autoestima, a motivação e o interesse, criando neles o sentimento de incapacidade e incompetência, levando-os a crises e paralisias, refletindo negativamente na relação ensino-aprendizagem, criando uma série de desafios aos trabalhadores da educação que precisam aprender a lidar e se relacionar com esse novo tipo de alunado, reconstruindo, recontextualizando e reformulando a ideia que têm de estudante universitário. 
Este não é um problema específico do campus de Picos, mas um fato generalizado, comum aos campi centrais e periféricos das instituições de ensino superior brasileiras, embora seja mais acentuado nos periféricos justamente pelo segmento social atendido, geralmente proveniente das comunidades carentes e das camadas populares. No caso do campus de Picos, seu contingente majoritário provêm da classe popular, que segundo o Critério Brasil ${ }^{4}$ podem ser classificadas como $\mathrm{C}$, D e mesmo $\mathrm{E}^{5}$, e sua bagagem socioeconômico cultural é profundamente afetada por defasagens e deficiências de variadas ordens.

Muitos desses estudantes têm um discurso pronto para justificar a falta de disciplina, a displicência com o estudo, os problemas de escrita e interpretação, a ausência do hábito da leitura, etc. Esses jovens (indivíduos que estão na faixa etária entre 18 e 24 anos, conforme classificação da Organização para a Educação, Ciência e Cultura das Nações Unidas -UNESCO) utilizam sua situação socioeconômica como justificativa e vitimização, consciente e/ou inconscientemente, esperando com isso obter facilitações burocráticas-culturais (burlar as avaliações, as normas, as regras, a disciplina inerente ao estudo e também abrandar o nível de exigência, utilizando de suas deficiências de formação, decorrentes da ausência ou precariedade de capital econômico, social e cultural) e flexibilização por parte dos docentes.

Essas foram constatações e análises realizadas durante o primeiro semestre do período letivo de 2010, resultando num levantamento de dados e estudo que teve início no segundo semestre desse mesmo ano letivo, estendendo-se até o primeiro semestre do período letivo de 2012, com alunos egressos nos cursos de Pedagogia, História e Matemática (nesse curso, especificamente, ministramos aulas até o segundo semestre de 2011) do campus de Picos, da Universidade Federal do Piauí. Durante as primeiras semanas de aula, os alunos foram e são provocados, através de questões que são formuladas oralmente e lançadas para as turmas, posteriormente registradas para comparação, análise e sistematizações, a refletir coletivamente sobre o que é estudar, o que é estudo, o que é ser estudante e como estudar (condições ideais e uma contraposição às condições reais, relativas as suas condições de classe). As colocações dos estudantes são preocupantes e esclarecedoras, como teremos oportunidade de averiguar.

A tabela abaixo demonstra o quantitativo de alunos com que trabalhamos no semestre de cada período letivo: 
Tabela 1: Quantidade de Alunos por Período Letivo

\begin{tabular}{|l|c|c|c|c|}
\hline \multirow{2}{*}{ Curso } & \multicolumn{4}{|c|}{ Quantidade de Alunos por Período Letivo } \\
\cline { 2 - 5 } & 2010.2 & 2011.1 & 2011.2 & 2012.1 \\
\hline História & 41 & 47 & 51 & 48 \\
\hline Pedagogia & 41 & 49 & 50 & 49 \\
\hline Matemática & 33 & 57 & 56 & ---- \\
\hline
\end{tabular}

Tabela 1: Quantidade de Alunos por Período Letivo

Fonte: Elaboração Própria, São Paulo, 2017.

Portanto, do segundo semestre do período letivo de 2010 até o primeiro semestre do período letivo de 2012 foram arguidos 522 estudantes ingressantes no ensino superior público, provenientes, em sua maioria, dos segmentos populares, afluindo de outros estados, através do SISU (Sistema de Seleção Unificada), como também dos cerca de 50 municípios vizinhos a cidade de Picos, além daqueles que residem no próprio município.

Realizamos uma avaliação em relação às respostas dadas aos questionamentos oralmente formulados, e as demais questões a partir deles desdobradas, considerando e classificando as respostas como: a) mais comuns; b) menos frequentes e c) diferentes/interessantes. A partir delas e das comparações estabelecidas, tecemos nossas análises e reflexões, realizando alguns apontamentos, com base em alguns dos principais estudos e pesquisas publicados que indiretamente nos auxiliaram na apreensão e construção de algumas das razões que condicionam os problemas identificados, procurando especificar as categorizações ontológicas imanentes referentes ao estudo, ao estudar, ao como se estuda e ao ser estudante.

\section{O ESTUDO, O ESTUDAR (COMO SE ESTUDA), O SER ESTUDANTE}

Conforme as informações colhidas a partir do segundo semestre do período letivo de 2010 até o primeiro semestre do período letivo de 2012, ao fazermos a provocação aos alunos dos cursos de História, Pedagogia e Matemática (relembrando que no caso deste último curso ministramos aula até o segundo semestre de 2011), indagando sobre o que entendiam por estudo, as falas a) mais comuns, foram: "ampliar conhecimento; adquirir conhecimento; aprender; saber"; b) as menos frequentes: "ir além do senso comum; trabalho; assimilação do conhecimento produzido pelos homens"; c) 
diferentes/interessantes: "nunca ninguém perguntou; nunca parei para pensar sobre isso; algo que já está pronto”.

Já sobre o estudar, as a) mais comuns, foram: "sinônimo de estudo"; b) diferentes/interessantes: "estudo algo que já está pronto, estudar algo que está sendo construído". É importante enfatizar que havia quase unanimidade entre os alunos em dizer que estudo e estudar eram sinônimos, não aparecendo falas menos frequentes semelhantes. Sobre ser estudante, as a) mais comuns, foram: "estudar; fazer atividades; cumprir compromissos"; b) menos frequentes: "ir para uma escola, uma instituição de ensino; pesquisar"; c) diferentes/interessantes: "ter tempo; não trabalhar".

Durante a explanação e justificativa oral dos alunos, registrávamos as definições emitidas no quadro, realizando e conduzindo uma reflexão dialógica, dialética e colaborativa sobre cada conceito. Com bastante frequência, mediante as discussões desencadeadas com as turmas, ouvíamos, de muitos alunos, as seguintes colocações: "nunca ninguém ensinou isso pra gente"; "nunca ninguém explicou desse jeito"; "nunca me provocaram a pensar dessa forma"; "Nossa!!!??? Esse é o significado?! Caramba!"

\section{O ESTUDO}

Iniciemos a análise e reflexão das definições dadas pelos alunos e como elas foram desconstruídas e reconstruídas por intermédio da dialogicidade e do pensar por contradição, procurando buscar o significado ontológico e teleológico de cada conceito e as mediações relacionadas às situações concretas, pois como afirma Marx, na Crítica da Economia Política, "o concreto é concreto por ser a síntese de múltiplas determinações, logo, unidade da diversidade". Tomemos, nessa perspectiva, o questionamento sobre $o$ que é o estudo.

Conforme demonstrado, as falas mais comuns em relação ao estudo o relacionam com conhecimento, aprendizado, saber; as menos frequentes apontam para a necessidade daquilo que poderíamos denominar de esforço sistematizador; já as diferentes/interessantes permitem inferir que os indivíduos, na sociabilidade capitalista da massificação e padronização do ser, agir, fazer, raciocinar mecânica e instrumentalmente, deixam de refletir/pensar dialética e contraditoriamente as situações concretas do real, não se espantam, não se admiram, mas aprendem, desde tenra idade, por intermédio de um processo de socialização de inculcação dos valores ideoculturais da classe proprietária que 
controla a produção material e espiritual, a naturalizar tudo o que é e foi socialmente criado, ou seja, produzido para atender a determinadas e específicas necessidades e interesses que, geralmente, não correspondem as necessidades e interesses de toda a humanidade.

Ainda que alguns dos alunos tenham esboçado características pertinentes relativas ao significado teleológico, isto é, causalidade finalística, do que é estudo, não sabiam contextualizá-las, explicá-las, justificá-las. Comumente suas falas vinham acompanhadas das seguintes complementações: "eu acho que é assim, mas não sei dizer porque. Não me pergunte por que, professor(a)". Isso ilustra o que afirmamos no parágrafo acima.

Em outro artigo ${ }^{6}$, fizemos algumas ponderações acerca do significado do estudo. Porém, agora a exigência é de maior precisão, numa perspectiva ontológica/teleológica, evidenciando a relevância de virtualidade germinal que a compreensão do conceito pode proporcionar para criação das condições subjetivas e objetivas para uma efetiva mudança atitudinal por parte do alunado e de todos aqueles interessados em ultrapassar a pseudoconcreticidade do real, como bem elucida Kosik (1995).

Toda ação humana é finalística, ou seja, teleológica, resposta a satisfação de necessidades inerentes e imanentes ao ser social, portanto, ontológicas, produzidas pelo processo de socialização e criação do mundo social e da dinâmica cada vez mais complexa das sociabilidades humanas, como evidencia Lukács pela didatização de Lessa (1996). Assim, o estudo, enquanto atividade humana, atividade produtiva, é resposta a uma necessidade, tendo em si mesma uma finalidade imanente, que é a sistematização da processualidade histórica-social dos homens, sempre em construção, em devir. Retomando as falas dos alunos, aqueles que, mesmo inconscientemente, associaram o estudo a trabalho, entendido por nós enquanto categoria ontológica e teleológica, aproximaram-se daquilo que podemos dizer ser a compreensão mais apropriada.

Sendo assim, enquanto trabalho ontológico, atividade produtiva teleológica, é imanente e inerente ao estudo o esforço, desconstruindo, desta maneira, a ideia de que corresponderia ao mérito de cada um. Após essa reflexão dialógica que realizamos com os alunos nas primeiras semanas de aula, não se aceita, nem se tolera, justificativas por parte do alunado do tipo: "mas eu me esforcei, professor(a), o(a) senhor(a) tem que levar isso em consideração". Subentende-se que o esforço é condição pressuposta, sine qua non ao estudo.

Há uma certa resistência e desconforto do alunado em relação a esse esclarecimento, sendo perceptível espanto, indiferença, desprezo, indignação, revolta. 
Também desmontamos a fala descontextualizada do "aprender brincando", pois o lúdico, o entretenimento são apenas momentos que compõem a unidade da diversidade do ensinoaprendizado, dada a impossibilidade de que todo o processo ocorra ludicamente. Algo já enfatizado por Durkheim (s/d), demonstrando ser o esforço um dos momentos inexorável do processo de estudo, reiterando nossa reflexão. Diz o autor: “(...) só podemos elevar-nos acima de nós mesmos através de um esforço mais ou menos penoso. Nada é mais falso e enganador do que a concepção epicuriana da educação, (...), segundo a qual o homem pode formar-se brincando e sem outro estímulo além da atração do prazer" (s/d, p. 67).

Juntamente ao esforço, está a disciplina, uma exigência posta pela atividade do aprender e apreender, embora no modo de produção capitalista e na lógica sistêmica metabólica do capital, e da sua correspondente pedagogia, adquira um significado opressor e não emancipador, como exemplificado por Enguita (1989). Há um outro lado da disciplina, muito distinto e mesmo antinômico da associação que geralmente se faz com seu contexto capitalista - de opressão, repressão, controle, poder -, ligado a busca de ser mais, de se humanizar e aperfeiçoar enquanto ser histórico-social, sociocultural, sociopolítico e ideocultural, biopsicoracioafetivo que somos.

Em sua positividade ontológica, a disciplina é uma das condições essenciais para que o homem se humanize e se eleve, superando as suas limitações presentes, colocando-se outros e novos problemas, de qualidade distinta, possibilitando-o, no dizer de Bertrand Russel, superar o drama (da sobrevivência) para viver, em plenitude, a tragédia (da existência). A disciplina é necessária para que, mais tarde, as condições para a autodisciplina, o autodidatismo, a autonomia e a liberdade possam, efetivamente, concretizarem-se, como demonstrado por Gramsci apud Nosella (2004).

Gramsci insiste na aprendizagem disciplinada do estudo do pequeno homem em formação como base instrumental de um intelectual rico e livre, evidenciando a necessidade insubstituível do cuidado, acompanhamento e condução disciplinar-amoroso feitos pelo educador, entendido como todo aquele que é responsável pelo indivíduo em formação, ou seja, pais, professores, tutores, enfim, educadores em geral.

Nosella explica que Gramsci é enfático ao demonstrar a:

positividade da disciplina diretiva e impositiva durante o período da prépuberdade, pois acredita que os bons hábitos assim adquiridos, longe de se contraporem ao exercício da liberdade e da autonomia do homem adolescente e maduro, constituirão o esteio de base para que essa liberdade e autonomia se concretizem e se exercitem de forma moderna, mais plenas e responsáveis. (2004, p. 133) 
A exemplificação dada por Nosella contribui para um entendimento inequívoco da reflexão de importância crucial desenvolvida por Gramsci, dispensando comentários. Ilustra Nosella:

Pense-se no uso da caneta: inicialmente é preciso 'coação externa' para o bom uso da caneta (e gramática). Se isso ocorrer corretamente, o jovem adolescente, no exercício de sua autonomia, longe de rejeitar a caneta (ora já incorporada como hábito e como segunda natureza), a utilizará para se expressar plenamente, isto é, para ser livre: por exemplo, escreverá poesias e poemas, contos e críticas, projetos e cálculos. (NOSELLA, 2004, p. 133)

Na mesma direção, podemos fazer uma aproximação com os estudos de Lahire (1997) sobre o sucesso escolar improvável das classes populares, onde fica patente que o aprendizado da disciplina - de forma consciente, impositiva, onde são estipulados pelos pais e/ou responsáveis os horários de brincar, estudar, assistir TV, etc, ou inconsciente, segundo as necessidades prementes no exercício da socialização -, que ele denomina de "ordem moral doméstica" e "formas de autoridade familiar", acabam compensando a ausência, insuficiência ou deficiência de capital cultural desse segmento de classe, algo que também é comprovado pela pesquisa desenvolvida por Setton (2005).

(Re)significado o estudo como trabalho, enquanto categoria ontológica e atividade produtiva teleológica, tratamos de esclarecer aos alunos que eles terão uma jornada dupla, quiçá tripla - considerando as atividades domésticas e a educação dos filhos -, de trabalho, agravada por sua condição econômico-social de classe, uma vez que um contingente considerável, quase absoluto, é proveniente do segmento popular, portanto, são trabalhadores estudantes e não estudantes trabalhadores, e por conta dessa situação concreta e suas implicações colaterais correlatas, terão de criar as condições para superarem as deficiências, debilidades e lacunas de sua formação anterior, principalmente ao tomarem consciência delas, e não utilizá-las como justificativa antecipada de um provável desempenho insuficiente e problemático. Seus esforços deverão ser, devido seu condicionante socioeconômico cultural de classe, necessariamente dobrados. 


\section{DO ESTUDO AO ESTUDAR - COMO SE ESTUDA}

Como exposto anteriormente, houve quase uma unanimidade entre os alunos em identificar o estudar (verbo) com o estudo (substantivo masculino). Porém, não são sinônimos. Enquanto verbo, estudar reporta a ação, logo, diz respeito ao como se estuda e o como envolve procedimentos mais adequados para a eficiência no e do estudo, como demonstrado por Ruiz (1980).

Inúmeras são as obras de metodologia do trabalho científico, como as de Severino (2007), Matos e Vieira (2001), dentre outras, que procuram auxiliar aqueles que se debruçam em superar a pseudoconcreticidade do real, dele se apropriando e sistematizando a fim de compreender as contradições e a dialeticidade da processualidade histórica-social do fazer-se homem dos homens. Daí o significado de metodologia (met=meta; ódos= caminho; logia=refletir sobre): refletir sobre os possíveis caminhos para se atingir uma determinada meta, sendo ela a definidora dos procedimentos mais adequados para o êxito do que se busca alcançar.

O grande problema é que esses procedimentos não são ensinados, ainda que devessem sê-lo, tanto que se parte desse pressuposto no ensino superior, qual seja, que o aluno já tem o domínio dessas técnicas e que as exercitou devidamente. Entretanto, esse "tipo médio de aluno" só existe enquanto abstração, tipo ideal, e não concretamente. O problema é que é justamente esse tipo ideal de aluno o parâmetro para a organização do trabalho e atividades acadêmicas, algo que necessita ser urgentemente repensado, ainda mais com o processo expansionista do REUNE (Reestruturação e Expansão das Universidades Federais), que acolhe um grande contingente proveniente das classes populares, ameaçando transformar os novos campi em meros Centros de Ensino, ameaçando a indissociabilidade entre ensino, pesquisa e extensão que caracteriza as Universidades Públicas, dentre outros fatores controversos, como expõem Lucas e Leher (2001).

As debilidades, deficiências e lacunas apresentadas na formação dos trabalhadores estudantes e dos filhos das camadas populares são geométrica e exponencialmente complexos e problemáticos, como demonstram os estudos de Pavão (2007), Britto (et.al. 2008), Zago (2006), Piotto e Alves (2011), Piotto (2008), dentre outros, com consequências as mais diversas, atingindo mesmo, além do cognitivo, socioeconômico e sociocultural, o afetivo e psicológico. Ilustrativo o caso de Marcos, citado por Piotto (2008), concernente às debilidades, deficiências e lacunas na sua formação escolar. Ele 
prestou onze vestibulares, em cinco anos, até que, finalmente, conseguiu ingressar no curso de Psicologia na Universidade de São Paulo (USP). Ele admite não saber o que era estudar e nem como deveria fazê-lo.

Também é elucidativo o caso da Escola Secundária de Monserrate, norte de Portugal, em Viana do Castelo. Um grupo de professores realizou um trabalho de avaliação do conhecimento acumulado e sistematizado pelos alunos concluintes do ensino fundamental II, através de aplicação de simulados. Os resultados foram preocupantes, pois evidenciou-se que os alunos "não têm hábitos de estudo e não sabe sequer como estudar" (MAMEDE, 2000, p. 99).

Através desses exemplos é possível verificar que, de fato, há uma ausência sociocultural do aprendizado do estudar, do como estudar, algo que parece se perpetuar na nova geração dos professores recém-formados, apontando para sérias e preocupantes lacunas tanto na formação dos estudantes em geral, quanto na dos professores, em particular. Algo que, infelizmente, não teremos condições de explorar no presente artigo, ficando como apontamento para aprofundamento e reflexão num outro momento, uma vez que estão inexoravelmente imbricados.

Ainda em relação ao como estudar, Ruiz (1980) elenca uma série de sugestões e dicas para a eficiência nos estudos, tais como: a) tempo para estudar; b) para descobrir tempo; c) programar a utilização do tempo; d) como aproveitar o tempo das aulas; e) como ler e selecionar o que se lê; f) vocabulário e eficiência na leitura, dentre outras, que podemos considerar como condições ideais de estudo. Porém, sabemos que essas condições, na maioria das vezes, não condizem com a situação concreta das circunstâncias e condições reais vividas e experimentadas pelos trabalhadores estudantes e filhos das camadas populares. É necessária uma adequação das condições ideais às reais.

Mas é preciso esclarecer que essa adequação só se torna viável caso os alunos se apropriem do conhecimento desses procedimentos e técnicas do trabalho científico, sistematizando-os e (re)significando-os através de uma (re)contextualização efetuada de acordo com a reflexão de suas condições socioeconômicas culturais, algo demonstrado por Rochex (1995) e Oliveira (1996), enxergando o valor do conhecimento em si mesmo; o papel que a instituição de ensino desempenha em sua formação e humanização; a emancipação da herança familiar no campo escolar (não reproduzir a história dos familiares) e social (construir a sua própria história e identidade), desenvolvendo e cultivando uma certa margem de autonomia. 
Essas adequações são as mais variadas. Um exemplo são os locais de estudar, podendo ser aproveitadas as filas bancárias, de transporte; esperas para atendimento; toillet, quando utilizado para necessidades fisiológicas mais demoradas, conforme depoimento de Lucimar, entrevistada por Pavão (2007). Locais que são considerados inusitados e improváveis, de modo geral, mas que tornam-se possibilidade de aproveitamento, ainda mais se as técnicas de leitura forem assimiladas, exercitadas e aplicadas.

O não saber estudar, não saber como estudar também revela muito a respeito das instituições escolares que não estariam cumprindo sua função social básica, que é ensinar, algo que pode ter parte de sua explicação no fato de que um contingente considerável dos próprios professores não teria consciência efetiva do que significa o estudo e o estudar. Porém, como dito anteriormente, não são os professores e sua formação nosso foco principal nesse estudo. Assim, faremos um breve comentário a respeito das instituições escolares e seu papel, a partir da reflexão desenvolvida por Gramsci, exposta por Nosella.

Segundo Gramsci apud Nosella, "a escola acelera a formação, é o sistema Taylor da educação, oferece um método" - ou pelo menos deveria oferecer -, "ensina a estudar" ensinar deveria ser sua função social precípua -, "acostuma a uma disciplina intelectual" coisa que, infelizmente, não procede, pois a visão distorcida da disciplina e a ênfase na sua negatividade acaba contribuindo, como vimos, para os modismos pedagógicos, como o do excesso de ludicidade -, "e jamais pode substituir o espírito de iniciativa no campo do saber”. (GRAMSCI apud NOSELLA, 2004, p. 103) Aqui, Gramsci entra em outro aspecto, que é o do autodidatismo, do qual falaremos um pouco mais adiante.

Vemos, portanto, que a instituição escolar aceleraria as potencialidades humanas e não as criaria, promovendo, através do aprendizado, a criação das condições favoráveis que impulsionariam o desenvolvimento. Em outras palavras, por intermédio das relações sociais (e de produção), na interação com o outro, o indivíduo é desafiado a se repensar, se reconstruir, a dar respostas aos problemas e contradições postos, a ir além, a explorar e descobrir suas habilidades, limites e capacidades, trabalhando-as, desenvolvendo-as e se superando, o que Vigotsky definiu como zona de desenvolvimento proximal.

Para Oliveira (2005), dentro da perspectiva da teoria histórico-cultural vigotskiana, a instituição escolar tem a potencialidade de criar as condições para o pleno desenvolvimento dos indivíduos, mas esse potencial apenas se realiza em ato caso exista, ao longo da escolarização, um ensino e trabalho escolar de qualidade que promovam o desenvolvimento. Portanto, não é qualquer ensino, mas sim aquele que apresenta as 
mediações qualitativamente adequadas que poderá contribuir para a plenitude do desenvolvimento dos indivíduos sociais. No dizer de Gramsci, "a escola é algo importante, mas complementar" à vida, à experiência de luta; "tayloriza o saber geral, no sentido de que organiza as partes, subdivide os pontos, interliga os atos pedagógicos de forma que a sequência produza um todo orgânico e superior”. (GRAMSCI apud NOSELLA, 2004, p. 103) É lastimável que ela não cumpra essa função tão primordial.

\section{SER ESTUDANTE}

Contextualizados e compreendidos o que é o estudo e o estudar, resta construir as mediações que ambos momentos processuais mantêm com o ser estudante, uma identidade e uma atitude que não corresponderiam, tão somente, numa perspectiva sociológica, a expectativas em relação a papéis sociais a serem desempenhados, reconhecidos e legitimados socialmente. $\mathrm{Na}$ verdade, na dimensão ontológica/teleológica com a qual trabalhamos, o ser estudante apresenta características imanentes que decorrem das exigências e necessidades imperativas das atividades produtivas do estudo e do estudar, ainda que compartilhemos da constatação de Grignon e Gruel (1999) de que os estudos ocupam um lugar variável na vida dos estudantes, não sendo todos estudantes no mesmo grau, principalmente quando consideramos os trabalhadores estudantes e os filhos das camadas populares e suas condições e delimitações de classe que, embora não intransponíveis, condiciona a longevidade escolar e, de certo modo, sua formação.

Quais seriam, então, as características imanentes do ser estudante? Retomando o que disseram os alunos dos cursos de História, Pedagogia e Matemática consultados, dentre o mais comum está o estudar, ainda que não soubessem precisar o significado implicado nessa atividade, e também cumprir compromissos e fazer atividades. Aqui, surge a noção implícita de regras, normas e expectativas que foram aprendidas e internalizadas durante o processo de escolarização, com raríssimas exceções, essencialmente comportamental, voltado ao condicionamento e adestramento do fazer e pensar que, geralmente, configura aquilo que se costuma considerar "bom aluno": obediente; cumpre com suas responsabilidades; desenvolve todas as tarefas solicitadas; assíduo, mesmo estando doente não falta; não conversa; não atrapalha o bom andamento da aula; disciplinado; segue todas as normas e regras e não contraria, nem afronta e enfrenta os professores, etc.. Por outro lado, também poderíamos considerar uma questão de estratégia 
de sobrevivência, de inteligência institucional e "conformismo estratégico", como demonstram Silva (1999) e Portes (2000), traduzidas enquanto capacidade de compreender e saber jogar com as regras do campo escolar.

Já as falas menos frequentes relacionavam o ser estudante com frequentar uma escola, uma instituição de ensino. Aqui chama a atenção a questão dos papéis institucionais, pois o espaço institucionalizado incorpora e exige, em si mesmo, determinados comportamentos e posturas daqueles que o ocupam, regulando as ações dos indivíduos, mesmo que de forma inconsciente. No caso, as instituições escolares, pela própria arquitetura espacial e organização do trabalho escolar, imprimem uma certa dinâmica para as relações sociais que se estabelecem e desenvolvem no seu interior, e os indivíduos, quando delas fazem parte, aceitam e incorporam esse dinamismo, naturalizando-o. No que concerne às falas diferentes/interessantes, para alguns dos alunos, ser estudante é ter tempo, não trabalhar. Essas externalizações merecem uma análise e reflexão mais densa.

Zago (2006) e Pavão (2007) demonstram, através de suas pesquisas, que para os alunos trabalhadores estudantes ou filhos da classe trabalhadora dos segmentos populares, assim como a grande maioria dos alunos do campus de Picos, dos cursos de História, Pedagogia e Matemática que participaram desse estudo, duas das características essenciais seriam ter tempo e o não trabalho, ligado a obtenção dos meios de subsistência para produção e reprodução das condições materiais de vida, com exceção das bolsas universitárias, de classificações variadas, sendo uma espécie diferenciada de trabalho, porque ligado aos processos e procedimentos acadêmicos, que acabam contribuindo para a permanência e subsistência mais imediata, complementada, na maioria das vezes, por auxílio familiar ou por trabalhos prestados pelos estudantes no tempo disponível devido à flexibilidade de horário permitida por esse tipo de trabalho, o que também possibilita uma participação mais condizente com a dinâmica exigida pela vida acadêmica. Esses bolsistas seriam estudantes que trabalham e não trabalhadores que estudam, usufruindo de algumas vantagens que podem vir a ser um diferencial para seus estudos e formação.

Porém, existem outras características não elencadas que consideramos fundamentais, expostas por Pavão (2007), Britto (et.al. 2008), Piotto e Alves (2011) e Gramsci apud Nosella (2004), das quais indubitavelmente compartilhamos e que são extremamente fundantes e fundamentais, considerando o contexto da vida acadêmica, onde a linguagem hegemônica, apesar dos vários tipos de linguagens, como demonstra Pinsky (2005) por intermédio da diversidade de fontes históricas, é a escrita, invariavelmente 
aperfeiçoada pela leitura, veículo primordial pelo qual se efetiva a difusão das ideias e do próprio conhecimento produzido cientificamente. Para além, são a escrita e a leitura que proporcionam as condições subjetivas e objetivas concretas para a autonomia e o autodidatismo, complementados pela instituição escolar, como exposto e enfatizado anteriormente através da transcrição de citação de Gramsci.

Para Britto (et. al. 2008), a principal característica desse "aluno novo", advindo das camadas populares, é que "as estratégias e procedimentos de estudo mais frequentes, bem como a representação que têm de verdade, estão sustentados por formas de conhecimento típicas do saber pragmático, em que predomina o senso comum" (BRITTO et. al. 2008, p. 788), daí as dificuldades apresentadas ao se depararem com textos e obras de leitura científica, como: compreensão; interpretação; vocabulário; capacidade de reproduzir e sintetizar; identificar as ideias centrais e as secundárias e reproduzi-las originalmente; problematizar e dialogar com os autores; etc., algo muito distinto do que Britto (et. al. 2008) denomina de "estudante clássico", que norteia toda a organização produtiva do trabalho acadêmico. Chega mesmo a afirmar, com base em estudos realizados por outros autores, que a "capacidade de estudo, manifestada principalmente pelo uso da escrita e da leitura, está muito mais relacionada às formas de acesso a cultura hegemônica e aos modos de argumentação científica que aos métodos de ensino da educação regular" (BRITO et. al. 2008, p. 787, grifo nosso).

Complementaríamos a assertiva de Britto (et. al. 2008) dizendo que está mais na capacidade de (re)leitura de mundo e (re)apropriação do patrimônio histório-ideocultural acumulado pela humanidade, superando a reprodução realizada no sistema educacional segundo os interesses e necessidades da classe social hegemônica, proprietária dos bens e meios de produção materiais e espirituais que, deste modo, condicionam o dinamismo das relações sociais e de produção da sociabilidade capitalista. Nas palavras de Saviani:

(...) Os conteúdos são fundamentais e sem conteúdos relevantes, conteúdos significativos, a aprendizagem deixar de existir, ela transforma-se num arremedo, ela transforma-se numa farsa. Parece-me, pois, fundamental que se entenda isso e que, no interior da escola, nós atuemos segunda essa máxima: a prioridade de conteúdos, que é a única forma de lutar contra a farsa do ensino. (SAVIANI, 2007, p. 55)

Esses conteúdos são entendidos por Saviani como prioridade porque: 
o domínio da cultura constitui instrumento indispensável para a participação política das massas. Se os membros das camadas populares não dominam os conteúdos culturais, eles não podem fazer valer os seus interesses, porque ficam desarmados contra os dominadores, que se servem exatamente desses conteúdos culturais para legitimar e consolidar a sua dominação. (SAVIANI, 2007, p.55)

Justamente, o domínio desses conteúdos pode criar as condições para a emancipação das classes populares, pois:

o dominado não se liberta se ele não vier a dominar aquilo que os dominantes dominam. (...) Mesmo veiculando a própria cultura burguesa, e instrumentalizando os elementos das camadas populares no sentido da assimilação desses conteúdos, eles ganham condições de fazer valer os seus interesses, e é nesse sentido, então, que se fortalecem politicamente. Não adianta nada eu ficar sempre repetindo o refrão de que a sociedade é dividida em duas classes fundamentais, burguesia e proletariado, que a burguesia explora o proletariado e que quem é proletário está sendo explorado, se o que está sendo explorado não assimila os instrumentos pelos quais ele possa se organizar para se libertar dessa exploração. (SAVIANI, 2007, p. 55 e 56)

Os estudantes, principalmente os "novos alunos", os das classes populares, precisam buscar desenvolver, de maneira exímia, um domínio da escrita e da leitura, uma vez que elas contribuem, como efetivamente demonstrado por pesquisa realizada por Piotto e Alves (2011), para o desenvolvimento autônomo e para o autodidatismo, essenciais no dinamismo da vida escolar e universitária. Analisando os resultados das entrevistas realizadas com alunas do curso de Pedagogia, e com base em outros estudos que tratam dessa problemática, as autoras chegaram a seguinte conclusão:

O gosto, o interesse e a habilidade com a leitura e a escrita foram de grande relevância para que conseguissem preencher algumas das lacunas do ensino a que tiveram acesso; também foram centrais para o desenvolvimento do que chamamos de autodidatismo, uma forma autônoma que essas estudantes desenvolveram de se responsabilizar pela própria formação; foram igualmente importantes para enfrentar as dificuldades do mundo acadêmico com as quais se depararam na universidade; além de terem representado, desde a infância e a adolescência, fontes de prazer, entretenimento e de elaboração de sentimentos. (PIOTTO e ALVES, 2011, p. 87)

A autonomia é uma conquista do próprio indivíduo, que se assume como livre, em construção, portanto, podendo e devendo ser mais, possível de se tornar capaz. As 
condições para a construção dessa autonomia combinam circunstâncias objetivas oportunidades dadas ou estrategicamente aproveitadas, como apontado por Silva (1999) e Portes (2000), tanto familiares como escolares - e subjetivas, não dependendo única e exclusivamente do querer ou vontade dos indivíduos, como assevera Vianna (2000), embora ainda tenham muitos educadores mal informados que acreditem nisso. Ilustrativa a afirmação de Gramsci:

toda pessoa se educa e se forma prevalentemente por si mesma; todo mundo é, antes de tudo, um autodidata.(...) A vida em geral, a ação, a experiência individual e coletiva são elementos que completam a escola, ou melhor, são completados pela escola, dependendo das situações, quer dizer, dependendo das classes sociais. (GRAMSCI apud NOSELLA, 2004, p. 103)

Portanto, a escrita e a leitura, bem como a autonomia e o autodidatismo são características imanentes ao ser estudante, que são multidimensionalizadas através da compreensão ontológica e teleológica do significado do estudo e do estudar, evidenciando que são três momentos constitutivos consubstanciadores de um único e mesmo processo, uma unidade da diversidade de sistematização da produção do conhecimento humano, construída pelas mediações entre as contradições dialéticas e dialógicas que perfazem as condições e circunstâncias materiais de produção e reprodução dos estudantes, que são trabalhadores estudantes, estudantes trabalhadores (bolsistas) ou filhos da classe trabalhadora que compõe as camadas populares.

\section{PARA ALÉM DAS CONDIÇÕES SOCIOECONÔMICAS CULTURAIS DE CLASSE... CONSIDERAÇÕES FINAIS}

A experiência vivida, conduzida e refletida pelos autores, utilizando, de modo recontextualizado, porque exercitada coletiva e colaborativamente, e não individualmente, o conceito de Donald Schon (1983) sobre a "epistemologia da prática" (conhecimento da ação; reflexão na ação; reflexão sobre a reflexão na ação), ainda que num curto espaço de tempo, já que teve a duração de algumas semanas, embora o estudo tenha sido desenvolvido por dois anos, produziu resultados interessantes que demonstram estarmos num caminho promissor, e que é possível provocar alguns desses alunos, a ponto de os fazer rever e reacomodar seus valores, construindo novas atitudes, o que consideramos um 
avanço significativo, pois sabemos que essas mudanças são lentas, gradativas e processuais, marcadas por avanços e recuos.

Nesse processo, as condições socioeconômicas culturais de classe condicionam, determinam, fundam o fazer-se homem dos homens, entretanto, é imprescindível e vital ressaltarmos que fundam, mas não o esgotam, não eliminando o poder e dever que os homens têm de lutar contra seu destino, pois é essa luta que plenifica de sentido suas vidas, desvelando o significado da assertiva de Marx de que "os homens fazem a sua história, mas não segundo sua vontade e sim sob condições e circunstâncias que dela independem", mas das quais necessitam, como condição vital, se apropriar e conhecer, em suas múltiplas e complexas mediações e contradições, a fim de que possam criar as condições objetivas para superar sua condição, garantindo sua realização enquanto seres humanos, dentro da plenitude possível.

Podemos dizer que a superação ou a possibilidade de ampliar os limites atuais dos alunos provenientes das camadas populares, ou dos trabalhadores estudantes, pode se dar através da tomada de consciência, da admissão e reconhecimento por parte desses estudantes, das razões, dos por quês de suas limitações, e a partir dessa compreensão, desconstruindo o discurso vitimista, discriminatório, excludente, justificador de compensações e facilitações de toda ordem, reúnam e criem as condições para a conquista da sua liberdade e dignidade humanas. Essa transcendência positiva exigirá, como condição, um trabalho exaustivo, com sacrifícios, abnegações, sendo inerente o esforço, o comprometimento, o reelencar de prioridades na vida, coisa que a maioria deles demora a admitir, reconhecer, aceitar e exercitar, colocando em prática, pois exige uma nova postura perante si mesmo e o mundo, uma metanóia (mudança radical de vida e mentalidade).

Dentre alguns dos resultados, exemplificamos com o desabafo de uma aluna do curso de Pedagogia, do segundo semestre de 2011:

Fiquei com muita raiva da senhora, depois tive raiva de mim mesma, porque vi que a senhora tava certa, e não foi fácil aceitar isso, me deu uma revolta tão grande... A gente usa a nossa condição econômica, social para justificar nossas falhas, mas é que é difícil admitir isso. Mas agora entendi o que a senhora quer dizer, eu me vi nas coisas que a senhora falou quando discutimos o documentário ${ }^{7}$. É difícil, mas eu vou conseguir.

E foram alguns desses frutos, reduzidos em quantidade, mas qualitativamente significativos, que nos fizeram repensar sobre a necessidade de reestruturação curricular 
das IES (Instituições de Ensino Superior), a fim de que possam, ao menos, auxiliar os estudantes provenientes das camadas populares a enfrentar as dificuldades vivenciadas que, como vimos, não são poucas. Essa reestruturação curricular seria experiencial e inicialmente aplicada nos cursos de licenciatura, principalmente os noturnos - devido o grande número de trabalhadores estudantes -, estruturados para a "formação de professores como intelectuais", como defendido por Giroux (1997) e também sustentado pelos presentes autores, onde os egressos teriam, durante o primeiro semestre, apenas três disciplinas, objetivando amenizar as deficiências, defasagens e lacunas trazidas do seu processo de escolarização anterior (nível fundamental e médio), como demonstram as pesquisas, os estudos e as análises teóricas citadas, referenciadas neste artigo.

Como enfatizamos anteriormente, várias são as formas de linguagem que podem ser usadas para a comunicação social, mas, como é sabido, a que predomina no meio acadêmico é a escrita, pois é através dela que difundimos as ideias, o conhecimento e sistematizamos a produção material e imaterial da humanidade. Sendo assim, as três disciplinas de preparação e embasamento para a vida e dinâmica do ensino superior seriam: a) técnicas de redação, b) metodologia do trabalho/pesquisa científica (teórica e prática, com produção de artigos e tentativa de submissão para publicação em periódicos de produção científica reconhecidos academicamente) e c) gramática da língua portuguesa. Acreditamos que o período de um semestre, embora não elimine e supere todas as carências dos anos de escolarização precedente, possa ao menos servir de embasamento e suporte para um enfrentamento e construção de respostas e estratégias mais eficazes, que auxiliem na permanência, elevação da autoestima e aproveitamento do tempo dispendido nas graduações e nas atividades acadêmicas, tornando-os, efetivamente, produtivos e significativos.

Finalizando, dando continuidade ao intuito de auxiliar os estudantes das classes populares, sugerimos que de maneira autônoma e autodidata, procurem desenvolver um método de estudo tendo por diretriz as sugestões dadas por Ruiz (1980), a partir da reconstrução da apropriação do significado ontológico e teleológico do que é o estudo, o estudar e ser estudante, segundo as análises e considerações tecidas no presente artigo, refletindo sobre os condicionamentos e determinações impostos por sua condição de classe e as demais mediações que podem entreabrir as brechas possíveis de serem trabalhadas para adequar as condições ideais pressupostas as reais vividas, de modo a criar as condições objetivas que possibilitem o desenvolvimento de suas capacidades e potencialidades humanas, plenificando de sentido sua formação. 


\section{REFERÊNCIAS}

BARRETO, Raquel Goulart; LEHER, Roberto. Do discurso e das Condicionalidades do Banco Mundial, a educação "emerge" terciária. Revista Brasileira de Educação (Impresso), v. 13, p. 423-436, 2008.

BOURDIEU, Pierre. Escritos em Educação. Org. Maria Alice Nogueira e Afrânio Catani.

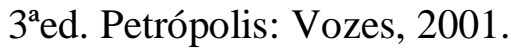

BRITTO, Luiz Percival Leme; SILVA, Edineuza Oliveira; CASTILHO, Katlin Cristina de; ABREU, Tatiane Maria. Conhecimento e formação nas IES periféricas perfil do aluno “novo” da educação superior. Avaliação, Campinas, v. 13, n 3, p. 777-791, nov. 2008.

COSTA, Márcio; CUNHA, Marcela Brandão. Estudantes pobres recém-chegados ao ensino superior : o que pensam os próprios? Revista Contemporânea de Educação, v. 3, p. 7, 2007.

DURKHEIM, Emile. Educação e Sociologia. Lisboa: Edições 70, s/d.

ENGUITA, Mariano Fernandez. A Face Oculta da Escola: educação e trabalho no capitalismo. Trad. Tomaz Tadeu da Silva. Porto Alegre: Artes Médicas, 1989.

GENTILI, Pablo. A. A.; SILVA, Tomaz Tadeu da. Neoliberalismo, Qualidade Total e Educação: visões críticas. 13 ${ }^{\mathrm{a}}$ ed. Petrópolis, RJ: Vozes, 2010.

GIROUX, Henry A. Os professores como intelectuais - rumo a uma pedagogia crítica da aprendizagem. Trad. Daniel Bueno. Porto Alegre: Artmed, 1997.

GRIGNON, Claude; GRUEL, Louis. La vie étudiante. Paris: Presses Universitaires de France, 1999.

JIMENEZ, Susana Vasconcelos e MAIA FILHO, Osterne. A Chave do Saber: um exame crítico do novo paradigma educacional concebido pela ONU. In: JIMENEZ, Susana V. e 
RABELO, Jaqueline (Orgs.) Trabalho, Educação e Luta de Classes: a pesquisa em defesa da História. Fortaleza, Ceará: Brasil Tropical, 2004.

KOSIK, Karel. Dialética do Concreto. $6^{\mathrm{a}}$ reimpressão. Trad. Célia Neves e Alderico Toríbio. Rev. Célia Neves. Rio de Janeiro: Paz e Terra, 1995.

LAHIRE, Bernard. Sucesso escolar nos meios populares: as razões do improvável. São Paulo: Ática, 1997.

LESSA, Sérgio. A Ontologia de Lukács. Maceió: Edufal, 1996.

LOMBARDI, José Claudinei; SAVIANI, Demerval; SANFELICE, José Luis (Orgs.) Capitalismo, Trabalho e Educação. 3 ed. Campinas, SP: Autores Associados, 2005.

LUCAS, Luiz Carlos Gonçalves; LEHER, Roberto. Aonde vai a Educação Pública Brasileira? Educação \& Sociedade, Campinas-SP, v. XXII, n. 77, p. 255-266, 2001.

MAMEDE, Maria Antonieta. A Supervisão de um Centro de Aprendizagem. In, ALARCÃO, Isabel. (Org.) Escola Reflexiva e Supervisão - uma escola em desenvolvimento e aprendizagem. Portugal: Porto Editora, 2000. (Coleção Cidine, 14)

MATOS, Kelma S. L.; VIEIRA, Sofia L. Pesquisa Educacional: o prazer de conhecer. Fortaleza: Demócrito Rocha: Eduece, 2001.

NOSELLA, Paolo. A escola de Gramsci. 3. ed. rev. e atual. São Paulo: Cortez, 2004.

OLIVEIRA, Marta Kohl de. Pensar a educação: contribuições de Vygotsky. In, CASTORINA, J. A. (e cols.) Piaget e Vygotsky: novas contribuições para o debate. São Paulo: Ática, 2005.

OLIVEIRA, Marta Kohl de. Escolarização e organização do pensamento. Revista Brasileira de Educação, (3), 1996, 97-102. 
PAVÃO, Andréa. Universidade e setores populares: identidades, motivações, projetos e sociabilidades. In: DAUSTER, Tânia. Antropologia e Educação: um saber de fronteiras. 1 ed. Rio de Janeiro: Forma \& Ação, 2007. (Fundamentos da Educação; 4)

PINSKY, Carla Bassanezi. (Org.) Fontes Históricas. São Paulo: Contexto, 2005.

PIOTTO, Débora Cristina; ALVES, Renata Oliveira. Estudantes das camadas populares no ensino superior público: qual contribuição da escola? In: Psicologia Escolar e Educacional (Impresso), v. 15, p. 81-89, 2011.

PIOTTO, Débora Cristina. Trajetórias escolares prolongadas nas camadas populares. Cadernos de Pesquisa (Fundação Carlos Chagas. Impresso), v. 38, p. 701-707, 2008.

PORTES, Écio Antonio. O Trabalho escolar das famílias populares. In. NOGUEIRA, Maria Alice; ROMANELLI, Geraldo; ZAGO, Nadir. Família e escola: trajetórias de escolarização em camadas médias e populares. RJ, Petrópolis: Vozes, 2000.

REGO, Teresa Cristina. Configurações sociais e singularidades: o impacto da escola na constituição dos sujeitos. In, REGO, T. C. (Org.); OLIVEIRA, M. K. de (Org.) ; SOUZA, D. T. R. (Org.) . Psicologia, Educação e as Temáticas da Vida Contemporânea. $1^{\text {a }}$ ed. São Paulo: Editora Moderna, 2002.

ROCHEX, Jean-Yves. Le sens de I'experience scolaire. Paris: PUF, 1995.

RUIZ, João Álvaro. Metodologia Científica - Guia para eficiências nos estudos. São Paulo: Atlas, 1980.

SAVIANI, Dermeval. Escola e Democracia: teorias da educação, curvatura da vara, onze teses sobre a educação política. 39 ed. Campinas, SP: Autores Associados, 2007. (Coleção Polêmicas do Nosso Tempo; v. 5)

SCHON, Donald. The reflective practitioner. Nova York: Basic Books, 1983. 
SETTON, Maria da Graça Jacintho. Um Novo Capital Cultural: Pré-Disposições e Disposições à Cultura Informal nos Segmentos com Baixa Escolaridade. Educação \& Sociedade. Campinas, vol. 26, n. 90, p. 77-105, Jan./Abr., 2005.

SEVERINO, Antonio Joaquim. Metodologia do Trabalho Científico. $23^{\mathrm{a}}$ ed. rev. e atual. São Paulo: Cortez, 2007.

SGUISSARDI, Valdemar. Universidade pública estatal: entre o público e o privado/mercantil. Educação \& Sociedade, Campinas, v. 26, n. 90, p. 191-222, jan./abr. 2005.

SILVA, Jailson de Souza. Por que uns e não outros? Caminhada de Estudantes da Maré para a Universidade. Departamento de Educação da PUC do Rio de Janeiro, 1999. Tese (Doutorado em Educação), p. 120-148.

VIANNA, Maria José Braga. Longevidade escolar em famílias de camadas populares: algumas condições de possibilidade. In, NOGUEIRA, Maria Alice; ROMANELLI, Geraldo; ZAGO, Nadir. Família e escola: trajetórias de escolarização em camadas médias e populares. RJ, Petrópolis: Vozes, 2000.

ZAGO, Nadir. Do acesso à permanência no ensino superior: percurso de estudantes universitários de camadas populares. Revista Brasileira de Educação. v.11. n 32. Maio/Ago. 2006, p. 226-237.

\footnotetext{
1E-mail: iaeldeo@gmail.com. Mestre em Ciências Sociais. Professora Assistente da Universidade Federal do Piauí. Departamento de Educação.

2E-mail: rra2@cin.ufpe.br. Doutorando em Ciência da Computação. Pesquisador da UFPE. Professor Assistente da Universidade Federal do Piauí. Departamento de Sistemas de Informação.

${ }^{3}$ SISU (Sistema de Seleção Unificada); PROUNI (Programa Universidade Para Todos); REUNE (Reestruturação e Expansão das Universidades Federais).

${ }^{4}$ A classificação de classes sociais utilizada no Brasil segue o estabelecido no Critério de Classificação Econômica Brasil, ou Critério Brasil. O Critério Brasil define as classes sociais em função do poder de compra e consumo de determinados itens (vide no site referenciado). Se uma família tem acesso a cada um dos itens, ela ganha pontos, que são somados e comparados com uma tabela. A classe social desta família é determinada pelo número de pontos que ela conseguir somar. Segundo esse critério, existem sete classes
} 
econômicas diferentes (A1, A2, B1, B2, C, D, E). http://www.logisticadescomplicada.com/as-classes-sociaise-a-desigualdade-no-brasil/

${ }^{5}$ É ilustrativo o caso de uma aluna do curso de Matemática. Foi realizada uma atividade analítica-reflexiva sobre o filme Matrix. A aluna em questão não atingiu a média. As colegas de sala vieram nos procurar para dizer que a mesma nunca tinha assistido um filme na vida, pois no lugar onde morava não havia energia elétrica e não tinha televisão, muito menos DVD. E pediam outra chance para que ela pudesse refazer a atividade.

${ }^{6}$ SOUZA, Iael de; AZEVEDO, R. R.; MONTEIRO, F. G. C. Pro dia Nascer Feliz! Essa é a vida que eu quis?!... Uma reflexão e alguns apontamentos. Revista Reflexão e Ação (Online), v. 21, p. 275-301, 2012.

${ }^{7}$ Trata-se do documentário Pro Dia Nascer Feliz, de João Jardim. Uma análise dessa produção fílmica pode ser encontrada em outro de nossos artigos, citado na nota anterior.

RECEBIDO EM: Setembro de 2016

APROVADO EM: Dezembro de 2016 